\title{
THE IMPORTANCE OF MILK AS A FOOD
}

\author{
BY W. H. JORDAN,
}

Director, New York Agricultural Experiment Station.

This people is now taking account of its resources, and in our analysis of the situation forced upon us by the demands of war we have discovered some of our weaknesses. One of these is the woeful lack of knowledge of nutrition, and another is that we are beyond all measure a wasteful people. The war is a great national calamity, but in the midst of its evils there will come to us certain benefits which in part will be the great awakening we have had to our bad eating habits, our poor economy and our lack of an efficient administration of our food supplies.

The great problem which really faces us is both the production of food energy and its utilization in such a way as will secure the maximum benefit. While we must, of course, consider the constructive value of foods and certain peculiar physiological relations, the dominant question relates to the store of energy or, using a more conmon term, of fuel with which to maintain human activities both at the seat of war and with our own people.

We naturally ask then what production most fully conserves our resources. I am convinced that the dairy industry should receive unusual consideration and encouragement under the circumstances in which we find ourselves. My reasons for my belief are these:

First. It has been shown beyond question, as Dr. McCollum has pointed out, ${ }^{1}$ that milk is an exceedingly important food for all of us and especially for young children and all persons who have not reached the adult stature. This is true because it contains certain essential compounds, the nature of which is not known, that are absolutely necessary to growth-compounds which are not furnished in such abundance in any form of meat product. The state which I represent has approximately eight million persons in its cities, and it would be nothing short of a calamity if there should come to us a milk famine, or anything approaching it, because of the effect upon the physical development of the young in those cities.

${ }^{1}$ See page 95. 
Second. With the exception of pork, in which the fats are the dominant compounds, milk is the cheapest animal food in the market at the prices which now prevail. For some reason the public is exceedingly sensitive to any increase in the price of milk, while it treats with comparative complacency an increase in the cost of meats, flour and other staple products. It is important, therefore, if we are to maintain the necessary supply of milk, that the public shall be educated to understand its relative value. A celebrated authority, Dr. Graham Lusk, has recently stated that a family of five cannot afford to purchase meat until it has bought three quarts of milk.

If the prevailing cost of milk production continues, producers must receive a higher price if the output is to be maintained at its present level and this means a larger cost to the consumer unless the expense of distribution is reduced. Consumers are urged on the ground of economy, and also in order to increase our export of meats, to substitute milk for meats in the diet. If this is done, milk production must be increased. Such an increase will be accomplished neither by declaring this to be a governmental policy nor by fixing the price of milk unless farmers find that the returns from their cows allow a living profit. The problem is therefore a consumer's problem unless the cost of distribution can be lessened.

Third. The food energy of milk is more economically produced than is the edible energy in any other animal product, with possibly the exception of pork. This is equivalent to the statement that there is returned for human utilization from the energy of the forage and grain consumed by animals a larger percentage in milk than in other animal products, with the possible exception mentioned. There is abundant data to show that the cow has a great economic advantage over the steer as a food producer.

Some years ago in attempting to study the influence of food upon the composition of the animal's carcass, I grew four steers on rations that were accurately measured and analyzed, and at the end of varying periods the animals were slaughtered and a careful separation and analysis was made of the edible portion. This has enabled me to calculate the relation between the energy of the digestible food and the energy in the edible meat product. With the younger animals, seventeen months, the available energy consumed was to edible energy stored as 11.6 is to 1 . With the older 
animals, twenty-seven months, the available energy consumed was to the edible energy stored as 13.4 is to 1 . The energy relations in the growth of the last ten months was available energy consumed to edible energy stored as 11 is to 1 . If we consider a single day's results of the mature animal where the gain is two pounds, the available energy consumed is estimated to be to energy stored as 6 is to 1 . If the steers which were analyzed had received a more intensive ration and therefore made more rapid growth, the energy cost of production would probably have been reduced.

At the New York Experiment Station records were made of the food consumed and the milk produced during sixty periods of lactation, involving twenty-seven cows. It should be stated that these are high grade cows and that the cost of production with such animals reaches its minimum. It was found, however, that the approximate food energy cost of the energy stored in the milk solids was approximately as 3 is to 1 . It should be stated, of course, that quite a large part of the food of both steers and cows is forage, which is not a vailable as food for man, and therefore the energy which is stored from these coarse materials is so much gain to the sum of human fuel. This is quite different when we consider the consumption by animals of the cereal grains that are available for human consumption. With these grains a greater economy is reached by the production of dairy products than of meat products. It is a very conservative statement to assert that under the very best possible conditions of production with both classes of animals, the cow is more than twice as economical in her use of food energy when we consider the output for human use than is the steer or sheep.

I am convinced, therefore, that in the eastern portion of the country or in any portion where large populations of cities are to be fed, the dairy industry should be encouraged in every possible way, not only because of the essential relations of milk to the welfare of growing individuals but because our cheese and butter should serve a useful and even a necessary function in our army and among the people with whom we are associated in this great conflict. 